\title{
Research on the Influence Mechanism of Career Insecurity on Individual Career Dynamics
}

\author{
Peiqi Wang * Bin Zhang and He Huang \\ University of Defense Technology, No.5 Guang Ming Road, Xi'an, Shanxi, China
}

\begin{abstract}
Career insecurity is widespread in individual career development. Career insecurity has both positive and negative effects on individual career dynamics. It has practical value to explore the influence mechanism between career insecurity and individual career dynamics for both individual career development and organizational performance. Through sorting out the relevant literature, this paper proposes two hypotheses on the influence of career insecurity on individual career dynamics. The negative impact of career insecurity on individual career motivation is mainly reflected in the reduction of organizational commitment, organizational trust, job satisfaction, employee performance, work input, innovative behavior, etc.; the positive impact of job insecurity on individual career motivation is mainly reflected in a low level of career insecurity can lead to social inertia such as absenteeism and increased escapism. this research plans the research methods and steps, laying a foundation for the next empirical study.
\end{abstract}

Keywords: Career Insecurity, Career Dynamics, Influence Mechanism

\section{Introduction}

The theory of career dynamics is also called career development view, which was first put forward by professor E.H. Schein[1]. Its essence is the interaction between the inner occupation (individual) and the outer occupation (organization), and the mutual cooperation, so that the needs of both sides can be satisfied, benefit from each other and develop. The narrow sense of career dynamics refers to the motivation of individual work. It is generated by a variety of related factors inside and outside individual career, which urges individuals to engage in work activities, and promotes the operation and development of work activities cycle by cycle, so as to achieve the work objectives of the countless sub forces formed by the resultant force. Internal motivation is composed of needs, interests, wills, values and world views, while external motivation is formed by factors such as social status, economic benefits and working conditions. Only when external forces are transformed into internal forces can they play a positive role. This study mainly focuses on the narrow sense of career dynamics, which refers to the integration of factors that can stimulate individuals to engage in work, develop themselves and realize organizational needs at the same time. Most of the researches on career dynamics are conducted from the perspective of a specific group's professional identity or career plateau. For example, a study on the professional identity of teachers (li

\footnotetext{
*Corresponding author: 463872349@qq.com
} 
Peng, a study on the motivation of teachers' career, 2010; Xue Yijun, Research on career dynamics of university counselors based on expectation theory, 2015). Careers insecurity is a subjective psychological feeling, which has an important influence on the individual's attitude and behavior. In general, career insecurity is a major source of career stress for individuals. The individual feels the career insecurity and falls into the negative emotion, which causes the negative behavior in the work and affects the career dynamics. There are many researches on individual negative work behaviors in the research field. For example, the degree of career satisfaction decreases, career involvement decreases, and career burnout increases. However, there is little research on the influence of career insecurity on individual career dynamics. The research on the influence mechanism of career insecurity on individual career dynamics can provide reference for the human resource management of organizations.

\section{Basic Theories}

\subsection{Career insecurity}

Scholars began studying career insecurity in the 1980s. According to scholars, career insecurity is the feeling of powerlessness caused by employees who are in a threatened work environment but still want to maintain their current work. They also point out that this kind of uncertainty comes from multiple directions. As long as employees face any job-related loss, such as loss of income, promotion opportunity, career development opportunity, status and colleagues, they will feel insecure about their jobs. Some scholars define it as "the subjective perception of the individual when the continuity of the present job is threatened", "It's the individual's fear of the threat of not being able to continue their current job." In general, these definitions of career insecurity focus on whether you can continue in your current job in the future. However, there are still some disputes over the definition of the category and no unified cognition has been formed. At present, the connotation of career insecurity can be summarized as follows:

Firstly, career insecurity is subjective and objective. Researchers in the field of organizational behavior tend to regard career insecurity as an objective situational phenomenon, independent of individual experience and interpretation. In other words, no matter how the individual perceives it, Career insecurity can be evaluated objectively and independently of the individual. For example, there are objective differences in career insecurity between regular employees and temporary employees. The form of temporary employment itself is an objective existence of career insecurity. Some researchers also believe that career insecurity is a subjective psychological phenomenon, which is the expectation of subordinates that their job survival will be threatened. It is full of subjectivity.

Secondly, career insecurity can be acute or chronic. Acute insecurities such as urgent job stressors, such as sudden mass layoffs, can trigger a sense of crisis. Chronic insecurity is a more common feeling, such as anxiety caused by high unemployment in the workforce, so career insecurity exists not only in organizations that are in a period of change, but also in organizations that don't seem threatening.

Thirdly, the career insecurity has the whole and the multi-dimensional distinction. Some scholars believe that career insecurity is a one-dimensional structure, which is the overall consideration of employees on whether to continue their current work. Some scholars also believe that career insecurity is multi-dimensional, including not only the fear of losing the job opportunity, but also the fear of the value characteristics brought by losing the job. 


\subsection{Factors influencing occupational motivation}

Career dynamics theory rejects the idea that the organization decides the demands of the career unilaterally. Instead, it believes that career development is realized by the process that the inner career and the outer career work together, and the inner career and the outer career match each other. An individual's career dynamics should consist of two major elements: first, the individual's internal drive, also known as the career anchor, which is subjective and includes values, interests, skills, etc.; The second is external driving force, such as industry classification, occupational orientation, social factors, etc., specific to the organizational level, including recruitment, training, promotion, compensation, punishment and other mechanisms. It is important to emphasize that the two do not exist in isolation, but interact with each other and eventually the external drive ACTS through the internal drive.

The career dynamics we discuss here is based on the premise that the career choice has been made clear, that is, a certain occupation has been selected, and then to explore what factors within this occupation can stimulate the individual to continue to maintain the confidence and driving force of the vigorous career development. In fact, he prefers the concept of psychological contract, that is, the expectation that exists between the organization and the individual that cannot be written down. Based on the concept of psychological contract, the factors affecting career dynamics can be summarized as follows: good working environment, safety and sense of belonging, promotion, training and development opportunities, value identification, remuneration, and the coincidence between task and career orientation, etc. Some scholars also equate occupational motivation with occupational motivation and define it as three dimensions: self-efficacy beliefs, person-job fit, and work engagement.

\section{Relational Hypothesis}

\subsection{Existing research conclusion}

The research on the influence mechanism of job insecurity on individual occupational motivation can be expressed by a model. Starting from the individual's psychological perception to work insecurity, exploring the impact on occupational motivation and its mechanism of action, as far as the work itself is concerned, how the complexity of job requirements affects the relationship between work safety and individual occupational motivation. As shown in Figure 1:

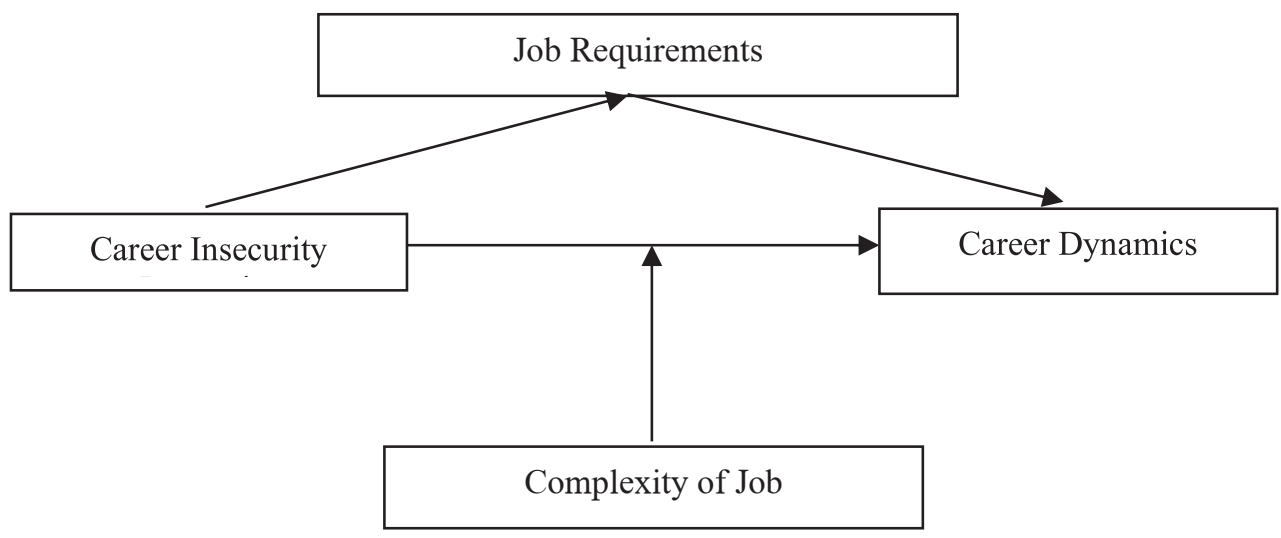

Fig. 1. The Model of The Effect of Job Insecurity and Individual Occupational Motivation. 
From the perspective of the mechanism of organization identification factors and work complexity factors in Figure 1 (according to existing research conclusions [2]), in fact, the impact of job insecurity on individual occupational motivation cannot be simply used to linear relationship It is said that there are many intermediate variables, such as organizational identity and work complexity as shown in the figure. Therefore, to study the mechanism of job insecurity on individual occupational motivation, it is necessary to first select the intermediary factors that have an impact on it.

You can refer to the existing research conclusions, such as: the job content and job requirements of different positions will directly affect the employee's work input level; under the Chinese background scenario, there is a significant negative relationship between job insecurity and organizational identity; There is a significant positive correlation between job safety and job engagement; organizational identity plays a partial intermediary role in the relationship between job safety and job engagement. From the data results, organizational identity cannot fully explain the relationship between the two. There are other possible explanations; job complexity can effectively regulate the relationship between the two, that is, when job complexity is at a low level, there is a significant positive correlation between job safety and job engagement; when job complexity level is relatively low At high times, there is a significant positive correlation between job safety and job engagement, and when the relative job complexity level is low, the positive relationship between job safety and job engagement is more pronounced [6].

According to existing research conclusions, job trust also has an impact between job insecurity and individual career motivation [7]. Work trust reflects the individual's willingness or belief to believe in and depend on others, and at the same time reflects the individual's willingness to take risks for the trusted party [8]. Employee's trust in the organization is a kind of employee's overall perception of trust in the organization as a whole. It is usually based on the employee's decision and action on the organization's leadership, as well as the organization's governance mechanism and incentive system to form the overall impression of the organization [9]. At work, employees rely on their organizations to provide them with a good working environment, reasonable salaries, and future growth opportunities, which forms employees' trust in the organization [6]. The increase in job insecurity will reduce employees' trust in the organization, which in turn will reduce employees' creative process investment and intrinsic motivation, impair their creativity performance, and then have a negative impact on individual career motivation.

\subsection{Hypothesis of negative impact of career insecurity on occupational motivation}

Since career insecurity is an organizational member's psychological expectation of future job sustainability, career insecurity will obviously have an impact on the individual's psychology and then have an impact on his/her behavior. A large number of empirical studies show that: high level of career insecurity can reduce organizational commitment, organizational trust, job satisfaction, employee performance, job involvement, innovation behavior, etc. This is a negative effect of career insecurity. The research in this aspect mostly USES the method of empirical research. For example, the study of Hultgren (2003) shows that career insecurity has a negative impact on motivation and organizational commitment. Holmgren, Sverker and Isaksson (1999) conducted a longitudinal study of 375 employees in a shrinking organization in Sweden and found that career insecurity has a negative impact on organizations and individuals. However, the empirical study on the relationship between career insecurity and job performance found that the relationship between the two was very complex, and Rosenblatt et al. (1999) found that the two were negatively correlated. At the same time, Wong et al. (2005) investigated the impact of career insecurity on organizational citizenship 
behavior and job performance in the context of China, and found that the impact depended on the nature of the enterprise and the trust of employees, etc. Therefore, it can be confirmed that career insecurity has a negative impact on individual career dynamics.

\subsection{Hypothesis of positive impact of career insecurity on career dynamics}

On one hand, career insecurity has a negative impact on individual career dynamics; on the other hand, empirical studies have shown that if work security is at a high level, it will have a negative impact on performance. For example, studies have shown that "low levels of career insecurity lead to increased absenteeism and escapism."[2] In fact, the findings can be found in classic theories of organizational behavior, such as "social loafing" in group behavior. Due to the diffusion of responsibilities, for example, in the performance evaluation, there is a lack of targeted assessment for individuals and a lack of differentiation in the distribution of benefits, which leads to a higher level of job security for individuals. Therefore, performance is reduced. Career insecurity should be in a balance, moderate career insecurity can stimulate the career dynamics of individuals, so that they can work hard and improve themselves.

\section{Empirical Design}

Research can use questionnaire survey method, select more than 20 teams to collect data. To avoid deviations in common methods, questionnaires can be filled out by employees and their team leaders. When investigating, first determine the team that needs to participate in the survey with the assistance of the human resources department of the enterprise, and obtain the list of team leaders and members. Then number the employees, and mark the number on the employee questionnaire and issue it to the employee corresponding to the number to fill out. At the same time, the name of the employee to be evaluated is marked on the leadership questionnaire and distributed to the corresponding team leader to fill in. Each leader may need to evaluate the professional motivation of multiple team members. After the questionnaire was recovered, the employee questionnaire and the leader questionnaire were matched according to the list number. Questionnaire respondents. The research can adopt the questionnaire survey method to select the individuals in specific organizations who are faced with the situation of post change adjustment, organizational re-organization or regional change for investigation. The selection of questionnaire can draw on the existing mature scale, such as the scale carried out by Lee eta in the context of China. [3] After the scale is selected, the initial modification can be made according to the survey object, and the modification method can be carried out with the method of expert review. After the first round of distribution, further screening of the question options can be conducted by using SPSS statistical software and factor analysis method to determine the scale questions. In the process of empirical design, the selection of scale is very important, and the particularity of occupation and the rationality of samples should be fully considered.

\section{Conclusion}

Through the research of the above methods, the following conclusions can be drawn: First, job insecurity has an impact on individual occupational motivation, and this effect is not simply a positive or negative correlation. Instead, there must be some intermediate variables. According to the existing research conclusions, these intermediate variables may be organizational identity, work complexity, organizational trust, employee creativity, etc.; second, they can make job insecurity feel negative for individual career motivation. Hypothesis of impact: Work insecurity has a negative impact on personal professional 
motivation by reducing organizational commitment, organizational trust, job satisfaction, employee performance, work input, innovative behavior, etc. Third, a certain amount of work insecurity can be made Individual career motivation has a certain role in promoting, that is, the assumption that it has a positive impact on individual career motivation can enable individuals to maintain a more positive attitude into work. After verifying the hypothesis, we can find the correlation between job insecurity and individual occupational motivation, and then ensure the subordinates' work safety in organizational management while avoiding excessive work insecurity and work safety. Reach a relative balance. On the one hand, it can stimulate the internal motivation of employees and make them actively face the work; on the other hand, it can also ensure a certain sense of crisis and jump out of the "comfort zone" to meet more challenges and changes and stimulate their creativity. Conclusion After verification, to verify the mechanism of job insecurity on individual occupational motivation, it is also necessary to select typical samples and conduct empirical research in conjunction with statistical analysis.

\section{Acknowledgements}

This work is supported by "2018 National Social Science Foundation of China 18BGL291”.

\section{References}

1. Y Sun. The internal mechanism of occupational motivation theory: based on the perspective of value chain. Enterprise Technology Development, 3, 99 (2008)

2. C X Liang. Research on the impact of employees' job insecurity and psychological empowerment on work input, 8 (2016)

3. A Biletm. A Model of Creativity and Innovation in Organizations. Research in Organizational Bahavior, 10(1) 123-167, (1988)

4. Y L Zhao, The mediating role of job insecurity in the relationship between employee self-perceived employability and psychological well-being. Tianjin Normal University. 5, (2018)

5. N Yao. Research on the relationship between job insecurity and job satisfaction based on organizational support. Zhejiang University of Technology, 6 (2012)

6. L Huang. Research on the influence mechanism of work safety on employees' work input. Knowledge Economy, 19111 (2019)

7. Z W Li, L H Chen, F R Wang. Research on the impact mechanism of job insecurity on employee creativity. Science and Technology and Economy, 10, 76-78 (2019)

8. J Leekc, L Hahnm. Empirical analysis of roles perceived leadership styles and trust on team members' creativity: Evidence from KoreanI CT companies Computers in Human Behavior, 42(C),149-156 (2015)

9. R C Nyhan, H A Marlowe Jr. Development and psychometric properties of the organizational trust inventory. Evaluation Review, 21(5):614-635, (1997)

10. X T Zheng, J T Shi Jintao, Zheng Xingshan. The influence of employee trust in their organization on their work attitude. Management Review, 20(11), 36-40 (2008) 